\title{
Work from Home - Boon or Bane to an Employee in Pandemic
}

\author{
Jutika Pavani \\ Student of MBA \\ Rishi UBR PG College for Women, Hyderabad \\ Submitted to the Rishi's Online National Conference \\ "Management Perspectives for Quality Outlook in the post COVID Era"
}

\begin{abstract}
The pandemic scattered the world, COVID-19, has rendered a large proportion of the workforce unable to commute to work. This has resulted in both employers and employees seeking alternative work arrangements. The ongoing health and economic crisis related to the COVID-19 pandemic and the required physical distancing measures force many firms to introduce telework (working from home) on a large scale. As we begin to take advantage of the relaxation in lockdown to resume work, revive our businesses or resurrect our social lives, companies and employees are trying to visualize the future of the workplace.
\end{abstract}

Typically, when IT employees work from home a significant number continue to operate from the office. Employees of a few companies did work entirely from home, but the number was not significant compared to the size of the organized sector. The lockdown changed all of this. This has given companies an opportunity to evaluate the pros and cons of this concept from a relatively long-term perspective and sparked off speculation that the workplace is likely to change. When everything is a priority, nothing is a priority. And as executives struggle to make sense of the post-COVID business environment, many find themselves leading from this gray area of indecision.

Adopting new work model will need a lot of improvisation and changes. However, it is well established fact that generally change is being resisted by humans as it makes them uncomfortable. This is to analyze the pros and cons of work from home in this typical situation and to have an idea of managing.

Keywords: Work from Home, Employees, Employers, COVID-19, Productivity, Teammates

\section{Introduction}

The Covid-19 pandemic changed most of the world in all the aspects and streams. Millions of people were lost jobs, and others rapidly adjusted to working from home as offices closed. Before 2020 a movement was brewing within knowledge-work organizations. Personal technology and digital connectivity had advanced so far and so fast that people had begun to ask, "Do we really need to be together, in an office, to do our work?" We got our answer during the pandemic lockdowns. Individuals, teams, entire workforces, can perform well while being entirely distributed. The Covid-19 crisis has opened senior leaders' minds to the idea of adopting WFA for all or part of their workforces.

Companies including TCS, Twitter, Facebook, Shopify, Siemens, and State Bank of India have announced that they will make remote work permanent even after a vaccine is available. The pandemic pushed companies and consumers to rapidly adopt new behaviors. 
As it has been an advantage of the relaxation in lock down to resume work, revive businesses, social lives, companies, employees are visualizing the workspace. Most of the employees in the organized sector continue to work during the lockdown but from work from home while the IT sector is familiar as they face this frequently but for many of the sectors this is difficult to adapt such environment. Working from home is attractive to some of the professionals as they save money, traveling time, food expenses, staying close to the family but in the current scenario it has been a various change in the professional.

While this scenario will be good for some extent, but the actual thing is different. India lacks in power supply which is not up to the mark for the companies working on critical projects. Data security and client privacy can be one of the criteria. There has been a big challenge to many of the companies in different sectors. People want to work from home, but companies are unlikely due to the data privacy of the companies and the clients.

\section{Definition}

Work from Home means an employee is working from their own place rather than working from office. Many companies having work from home policy that allows employees to do work from home either full time or part time. WFH is an alternate way of organizing task that may be defined as the work which can be performed from home (away from the traditional workplace such as factories or offices) and enables employees to access their labor activities using information technology. The crisis of Covid-19 has ensured that be it, employers or employees, everyone has some sort of idea about WFH, however, it largely varies based on different perceptions.

\section{Objectives}

- To examine an inclusive and sustainable WFH framework and the organizational consideration about the flexibility of employees and employers at their space.

- To understand the analysis of work from home of the employees from current pandemic situation and to provide high Productivity and effectiveness at their comfort spaces.

- To analyze the lack of Staff morale and team cohesiveness and coordination between teammates and establish a daily routine with increase of working hours.

\section{Literature Review}

Chauhan et al. 2020: THS can be provided in the following modalities: real-time videoconferencing; remote monitoring with instruments operated by patients (e.g., thermometer, blood pressure instrument, pulse oximetry), without HCWs' physical presence; and robotic carts, screens, or medical equipment controlled by HCWs (Celesti et al., 2020; Yang et al., 2020).

Kelly, 2020: While organizations have started to consider extending "working from home" (WFH) arrangements beyond the pandemic, this sudden and exogenous shift has the potential to cause dramatic, and still unknown, effects on workers' behavior, as well as their productivity and wellbeing.

Staples, Hulland, \& Higgins, 2020: Employee productivity is defined as the efficiency and effectiveness of individuals in completing tasks and work responsibilities. Effectiveness refers to the extent to which an employee can complete their responsibilities in accordance with a predetermined deadline. Whereas efficiency refers to the extent to which the individual can accomplish tasks and responsibilities without any waste of resources. 
Symonds 2020: Reported that $50 \%$ of higher education professionals in universities across the globe had switched some of their scheduled courses online, this number is only set to increase as the coronavirus continues.

Wang et al. 2020 found that teleworkers experienced a more positive sense of well-being and fewer jobrelated adverse effects on well-being. This varied by personality type, with individuals expressing more 'openness' to the idea of WFH being more likely to report positive outcomes. Importantly, strong social networks beyond work seem to be linked to higher levels of positive effects, indicating that the sense of 'physical isolation' from the working environment can be compensated by maintaining a strong social network. Additionally, WFH may provide tangible benefits of increased family time, especially for new mothers through a reduction of commutes and more time available to spend with children at home (Wang et al., 2020).

\section{Research Methodology}

The study is purely based on the responses of 80 respondents working from home belonging to different sectors during COVID 19. Data is collected during April 20-21, the time frame when all the employees are compelled to work from home. Majority of the respondents of this study are from teaching and IT sector. All the respondents of this study are working from home for one month continuously.

Secondary Data has been also collected from various journals, websites, and newspaper reports.

Nature of Study: Descriptive

Sample Size: 80 Employers and Employee respondents

Data Collection Tool: Questionnaire (10 questions on employee based and 10 questions on employer based)

Data Design: Convenient Random Sampling

Primary Data: sample collected from 80 aspirants

Secondary Data: Secondary data was collected from personal interview, articles, and research papers on the above subject.

\section{Hypothesis of the Study}

The present study will be the analysis done with the employers and employee in the organization level from different sectors:

- The significance is with the comfortless of the people to perform the productivity of the project.

- Significance of knowing the employee and employer's flexibility from the work from home.

- Significance of the interaction level of the teammates and coordination with them.

\section{Limitations}

- This study has been taken from the sample taken by survey from different streams and mostly from IT employee and employers.

- Most of the questioner is dedicated to the analysis of the work environment and how they are managing their work without out office and making the work done from their own place and knowing how it has been boon or bane to them.

\section{Data Analysis}

The study is to analyze the employee and employers work from home situation without office. 


\section{Employee}

1. Do you feel there is adequate communication from your teammates and team leaders?

Communication serves as the foundation of every fact of a business. Effective communication is communication between two or more persons with the purpose of delivering, receiving, and understanding the message successful. It is the process of information sharing between team members in a way that keeps in mind what you want to say and what your audience interprets.

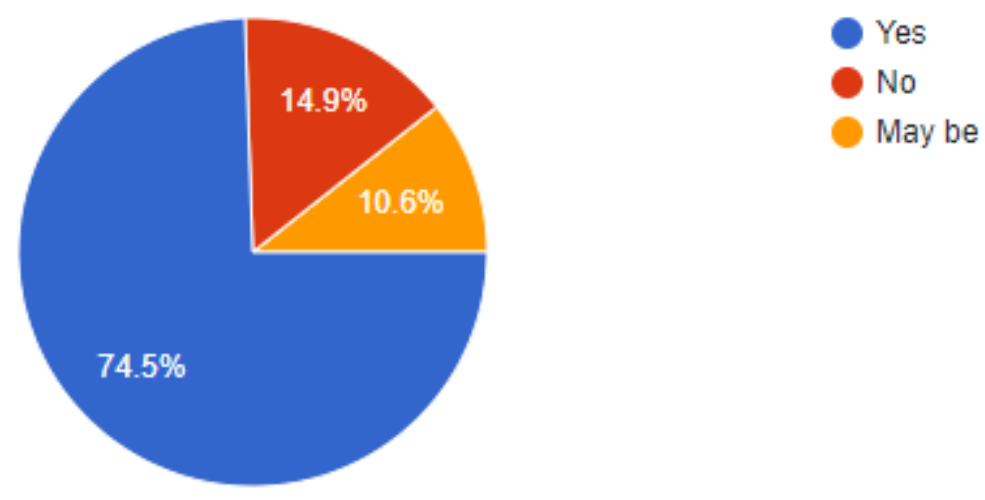

2. Do you have all the equipment and remote tools you need to complete your work to your usual ability? Get the infrastructure right. Do people have the requisite technology or access to it? Who has a laptop? Will those who do [have laptops] be able to dial into their organizations easily? Will they have the software they need to be able to do work, have conference calls. What about the employees who don't have laptops or mobile devices? How do you make sure that they have access to the resources they need to do work? Direct managers must very quickly ensure that every employee has full access, so no one feels left behind.

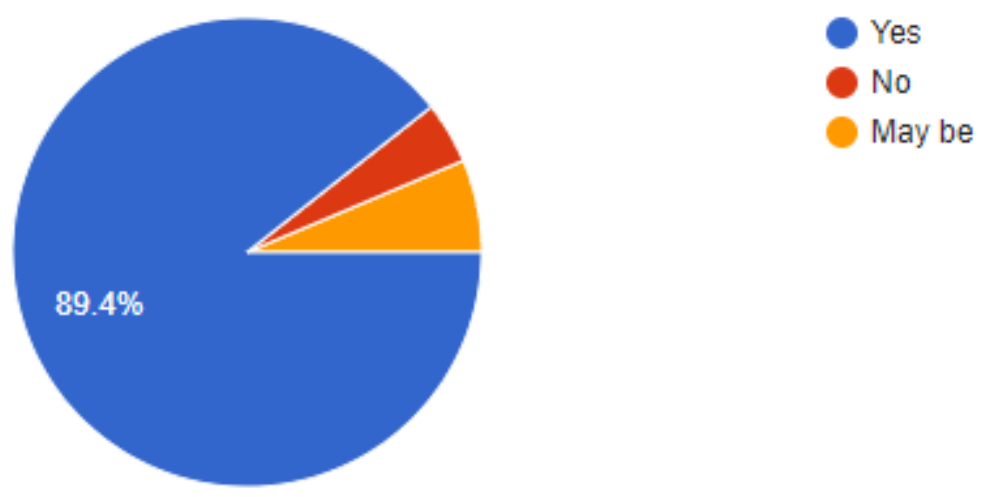

3. Do you feel as productive at home as you are at the office?

The researcher found that those working from home were 13 percent more productive than employees working in an office. Moreover, researchers found a 50 percent decrease in the attrition rate among telecommuters compared to on-site workers. 


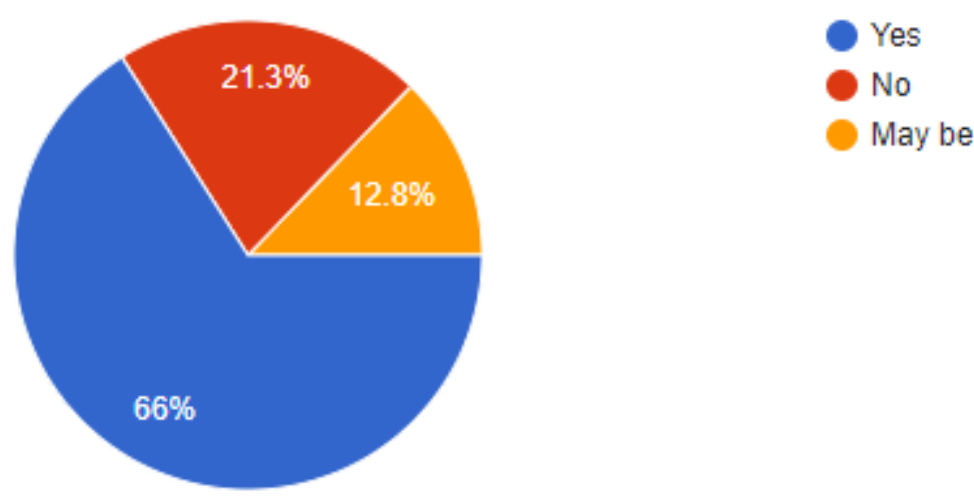

4. Do you have the appropriate amount of information to make correct decisions about your work?

Decision-making is the process of selecting the best possible option in each situation. Effective decisionmaking often requires you to: Identify many potential options, Anticipate possible outcomes, consider the needs or wants of others impacted by the decision.

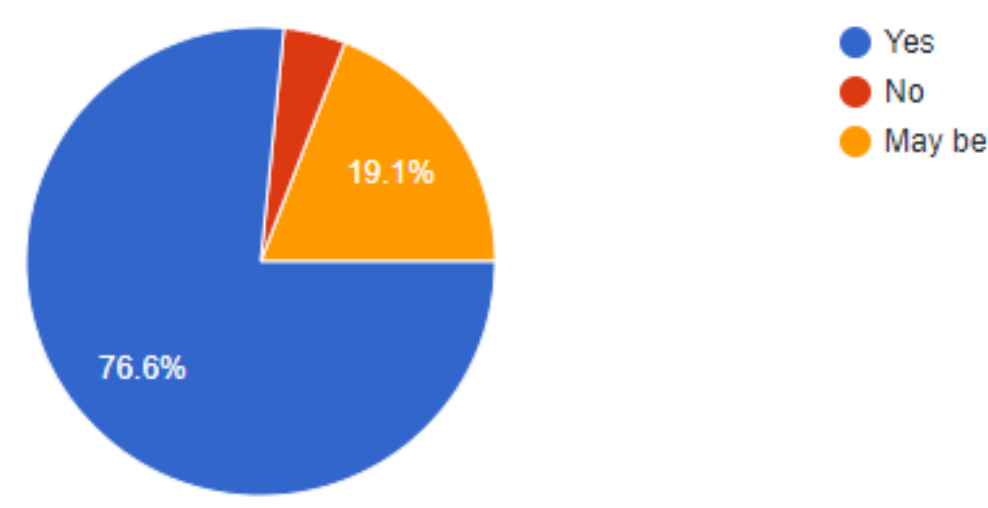

5. Do you look forward to returning to the office?

Working from home clearly has its place, but the drive among workers to be among peers and colleagues is extraordinary. The timeline for a full return to the office is fluid, but it seems that we have turned a corner. It is therefore critical that employers invest in the proper technologies to help them manage their space and keep their employees safe.

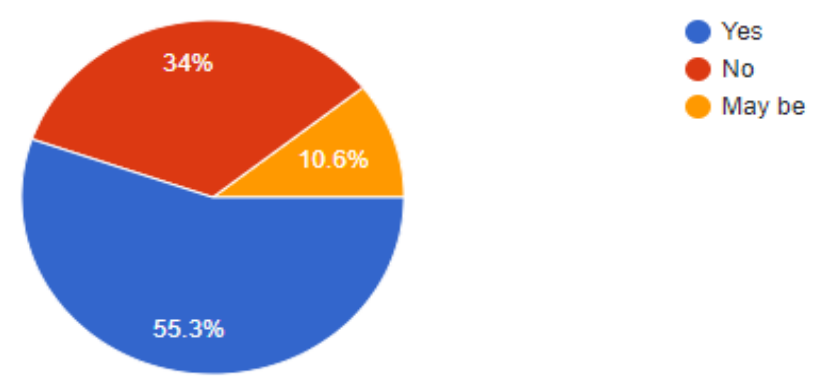

\section{Employer}

1. How satisfied are you with your current work from Home arrangements? 
15

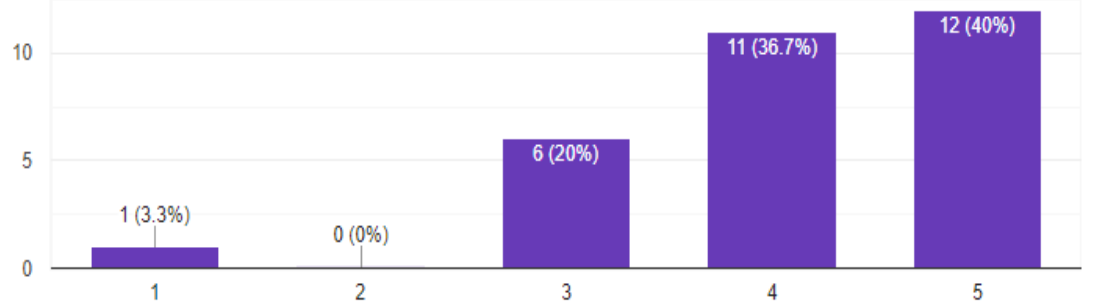

2. Compared to last week are you feeling more optimistic or pessimistic about work from home?

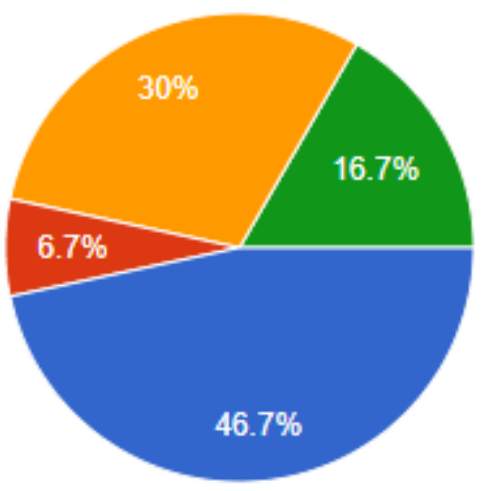

Optimistic

Pessimistic

All of the above

None of the above

Most of the state are optimistic towards the environment and as well as work from home.

3. How frequently you are facing challenges with your work?

There will be different challenges every day with the client, technology or it can also be people.

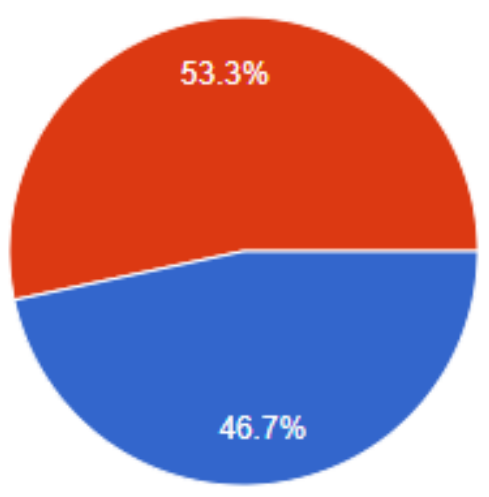

Frequently

Not frequently

4. How frequently you will be communicated with your teammates?

Mostly biweekly employers are communicating to their teammates for the work as well as motivational support. 

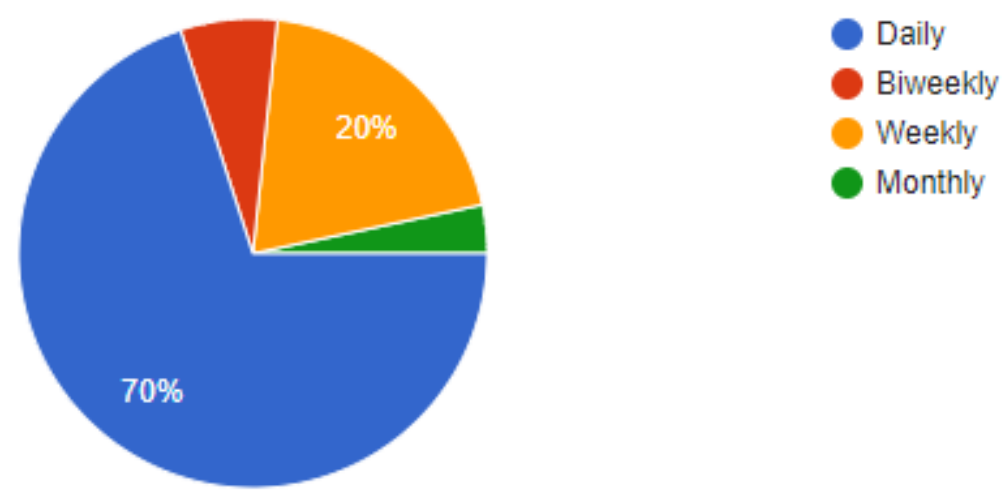

5. Will you continue work from home after post pandemic?

$46.7 \%$ says YES

$13.3 \%$ says NO
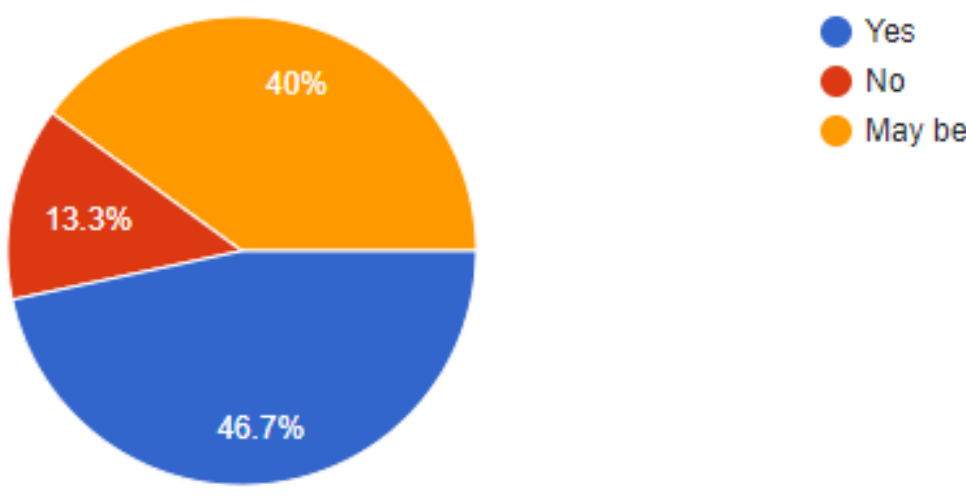

\section{Findings}

1. Work from home is boon when it is related to time, health, safety, travelling and other expenses and work from their own places.

2. People who cannot spend time with their families due to workload at office premises and the time taken in the travelling, but with work from home all these can be possible.

3. Work from home is also a bane, due to lack of communication with the teammates.

4. Lack of coordination and the effect of productivity, the motivation in the work premises cannot be gained in the work from home.

5. For some extent people and management are satisfied but most of the time there is no satisfaction and motivation to do work from home.

6. Work timings has been increased in few organizations to gain the productivity.

7. Due to connection issues or network issues the productivity will be affected, and the extension of work time should be increased.

8. The quality of the work might be affected and also the health due to the overload of work from home.

\section{Conclusion}

Work from home is the process of working from home through online using internet where work with specific project or a client. Employers have to define their objectives and outcomes through it and they have to be more proactive than before. Workers' rights at home having good equipment to perform good productivity. Managing work, health and safety while being at home and being updated towards technology. Job quality across all workplace's massive experimentation on WFH and learnings out of it will be one such 
thing to be looked after. The Work from home process will be dependent on different Stake holders, Work life balance, connection, and support.

With the shift to working from home, both during and after the pandemic, it will be necessary to ensure that home-workers are provided the same rights and benefits as if they were working at their employers' site, including equality of treatment in remuneration and other working conditions.

\section{References}

Hum Factors Ergon Manuf. 2021 Feb 12 : DOI: 10.1002/hfm.20889 [Epub ahead of print]

Tiago F. A. C. Sigahi, Bruno C. Kawasaki, Ivan Bolis, and Sandra N. Morioka Queensland University of Technology Brisbane Australia

Karanikas, Nektarios \& Cauchi, John (2020)

Asia Pacific Management Review

Available online 20 May 2021

Tri Wulida Afrianty, I. Gusti Lanang Suta Artatanaya, John Burgess

https://www.mbaskool.com/business-concepts/human-resources-hr-terms/16870-work-from-home.html www.ilo.org/wcmsp5/groups/public/---ed_dialogue/---act_emp/documents/news item/wcms_755686 https://www.researchgate.net/publication/344553863

https://www.business-standard.com/article/current-affairs/covid-19-impact-more-people-in-services-sectorto-work-from-home-in-future-120042600500_1.html

\section{Annexure}

\section{Employee}

1. Do you feel there is adequate communication from your teammates and team leaders?

Yes No May be

2. Do you have all the equipment and remote tools you need to complete your work to your usual ability? Yes No

3. Do you feel as productive at home as you are at the office?

Yes No May be

4. Do you have the appropriate amount of information to make correct decisions about your work?

Yes No

5. Do you look forward to returning to the office?

Yes No May be

\section{Employer}

1. How satisfied are you with your current work from Home arrangements?

Satisfied Not Satisfied Partially Satisfied Very Much Satisfied

2. Compared to last week are you feeling more optimistic or pessimistic about work from home?

Optimistic Pessimistic None of the above All the above

3. How frequently you are facing challenges with your work? 
Frequently Not frequently

4. How frequently you will be communicated with your teammates?
Daily
Weekly
Biweekly
Monthly

5. Will you continue work from home after post pandemic?

Yes No May be 